\title{
1995 Computer-Assisted Radiology Meeting
}

$\mathbf{T}^{\mathrm{h}}$ celebrations in 1995 to mark the centenary of Wilhelm Conrad Roentgen's discovery of $\mathrm{x}$-rays will look back on a major contribution to improved health care for the world's population. Recently, in addition to the classic x-ray (roentgen) equipment, more modern imaging devices have become indispensable tools in patient care. Similar to other developments in medical diagnosis and therapy, these advances were achieved by overcoming many technical, economic, and social problems. It will be interesting to review some of the significant aspects of this development in the centenary.

Toward the end of these 100 years, new developments in digital medical imaging have moved radiology to the hub of diagnostic procedures. Increasingly, image-driven methods augmented by computer and communication systems also facilitate effective therapeutic activities. Computer-assisted methods are leading radiology into the next century. They herald a health care system that will benefit the patient in particular and society in general. For example, during the next 10 years it can be expected that image-guided therapy supported by advanced computer and communication technology will become a driving force for a minimal invasive medicine.

All these developments are taking place internationally. Computer-Assisted Radiology (CAR) congresses since 1985, typically attended by experts from 25 to 30 different countries, have effectively contributed to the recognition of the potential of digital tools on a world-wide basis.

CAR 1995 will be supported by many professional institutions of radiology and informatics. In particular, the European Society for Picture Archiving and Communication Systems (EuroPACS), the International Society for the Planning of Radiological Departments (ISPRAD), and the Society for Medicine and Technology (MEDTECH) have joined CAR for 1995 to focus in a single comprehensive conference on digital tools in medicine. In addition to a strongly clinical CAR program, separate conference tracks relating to $\mathrm{PACS} /$ image managing and communications (IMAC) (EuroPACS), radiology office automation (ISPRAD), and imageguided therapy (MEDTECH) are being planned for this important event.

One hundred years of roentgen rays and 10 years of CAR, the traditional and the modern, will be celebrated on June 21 through 24, 1995 in the historic settings of Berlin, Würzburg, and Lennep. The Symposium Committee includes Ludovico Dalla Palma, University of Cattinara, Trieste, Italy; Roland Felix and Karl-Jurgen Wolf, Free University of Berlin, Germany; Kiyonari Inamura, Osaka University, Osaka, Japan; Carl C. Jaffe, Yale University School of Medicine, New Haven, CT; Takahiro Kozuka, Osaka University Hospital, Osaka, Japan; Heinz U. Lemke, Technical University of Berlin, Germany; Alexander R. Margulis, University of California, San Francisco, CA; Michel Osteaux, Free University Hospital of Brussels, Belgium; and Horst Sack, University Hospital of Essen, Germany.

Integrated into the events of the Symposium will be Industrial Exhibition (companies demonstrate their products, systems, and services), Scientific Exhibition "work in progress" (research institutions display innovative CARrelated projects) and Poster Exhibition.

The Honorary President of CAR 1995, Professor Alexander Margulis, and the Symposium Committee invite you to participate in this outstanding centennial event. For further information, contact Professor Heinz U. Lemke, Technical University of Berlin, Institute for Technical Informatics, Sekr. CG FR 3-3, Franklinstr. 28/29, D-10587 Berlin, Germany; telephone, 49-30-314 73 100; fax, 49-30-314 21103.

Heinz U. Lemke Technical University of Berlin Berlin, Germany 